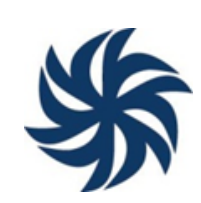

\title{
ADAPTACIÓN Y CONSENSO: EL PARLAMENTO URUGUAYO EN LA PANDEMIA DEL CORONAVIRUS
}

\section{ADAPTATION AND CONSENSUS: THE URUGUAYAN PARLIAMENT IN THE CORONAVIRUS PANDEMIC}

\section{ADAPTAÇÃO E CONSENSO: O PARLAMENTO URUGUAIO NA PANDEMIA DO CORONAVÍRUS}

\author{
Daniel Chasquetti ${ }^{1}$
}

\begin{abstract}
Resumen: Las asambleas legislativas de los países democráticos han tenido graves dificultades para cumplir con sus prerrogativas constitucionales durante la pandemia del coronavirus. Los estudios recientes muestran que los problemas más dramáticos están vinculados con la deliberación pública del proceso legislativo y el control de los poderes ejecutivos. El Parlamento uruguayo puede ser observado como un outlier debido al posicionamiento asumido por los principales actores. Ante la situación de riesgo, los partidos políticos establecieron un sólido consenso en la arena parlamentaria en apoyo a la estrategia de confinamiento voluntario del gobierno. A medida que el virus fue controlado, el país ingresó en una etapa de nueva normalidad política en la que el Parlamento incrementó sus actividades y el tratamiento de iniciativas que reactivaron el debate entre el gobierno y la oposición.
\end{abstract}

Palabras clave: Coronavirus; Pandemia; Legislaturas; Parlamento; Uruguay.

Abstract: The legislative assemblies of democratic countries have had serious difficulties in fulfilling their constitutional prerogatives during the coronavirus pandemic. Recent studies show that the most dramatic problems are linked to public deliberation of the legislative process and the control of executive powers. The Uruguayan Parliament can be seen as an outlier due to the position assumed by the main actors. Faced with the risk situation, the political parties established a solid consensus in the parliamentary arena in support of the government's strategy of voluntary confinement. As the virus was controlled, the country entered a stage of new political normality in which Parliament increased its activities and the treatment of initiatives that reactivated the debate between the government and the opposition.

Key words: Coronavirus; Pandemic; Legislatures; Parliament; Uruguay.

Resumo: As assembleias legislativas de países democráticos tiveram sérias dificuldades em cumprir suas prerrogativas constitucionais durante a pandemia do coronavírus. Estudos recentes mostram que os problemas mais dramáticos estão ligados à deliberação pública do processo legislativo e ao controle dos poderes executivos. O Parlamento uruguaio pode ser visto como um outlier devido à posição assumida pelos atores principais. Diante da situação de risco, os partidos políticos estabeleceram um sólido consenso na arena parlamentar em apoio à estratégia do governo de confinamento voluntário. Com o controle do vírus, o país entrou em uma fase de nova normalidade política em que o Parlamento intensificou suas atividades e o tratamento de iniciativas que reativaram o debate entre o governo e a oposição.

Palavras-chave: Coronavírus; Pandemia; Legislaturas; Parlamento; Uruguai.

1 Prof. Titular. Doctor en Ciencia Política (Udelar). Contacto: daniel.chasquetti@cienciassociales.edu.uy, dchasquetti@gmail.com 


\section{Introducción}

La aparición del coronavirus en el mundo impuso desafíos cruciales a los poderes legislativos. En muchas democracias, los parlamentos dejaron de sesionar por varias semanas y sólo retomaron sus funciones mediante la introducción de nuevas tecnologías no siempre eficientes. En otros casos, los parlamentos perdieron espacio ante el avance de poderes ejecutivos con vocación dominante. Los estudios recientes sobre estos problemas muestran que la pandemia ha erosionado fundamentalmente dos dimensiones del trabajo parlamentario: la deliberación legislativa y la capacidad de control sobre el gobierno. Los parlamentos de Bélgica e Israel fueron sorprendidos en medio de una crisis política y su capacidad de reacción fue lenta y poco consistente (BAR-SIMAN-TOV, 2020) (POPELIER, 2020). Los parlamentos de Hungría y Polonia fueron incapaces de reaccionar ante la estrategia de los ejecutivos de aprovechar el nuevo escenario para introducir reformas antiliberales en la constitución (DRINÓCZI; BIEŃ-KACAŁA, 2020) (SEROWANIEC; WITKOWSKI, 2020). Las legislaturas de Brasil y Suiza tampoco pudieron influir sobre la estrategia sanitaria de su respectivos gobiernos pese a la introducción de nuevas tecnologías para sesionar o votar en forma remota (PINHEIRO; ILARRAZ; MESTRINER, 2020; UHLMANN; SCHEIFELE, 2020).

El presente ensayo analiza la experiencia de la legislatura de Uruguay durante la crisis sanitaria del COVID-19. Este estudio muestra que, a diferencia de los casos antes mencionados, el Parlamento uruguayo no sufrió un déficit de deliberación legislativa como tampoco perdió la capacidad de control sobre el gobierno. En cierto modo, la legislatura uruguaya puede ser observada como un caso outlier del comportamiento típicamente marginal mostrado por los poderes legislativos democráticos durante la pandemia.

El proceso parlamentario uruguayo marzo-agosto puede dividirse en dos etapas bien diferentes. La primera va desde la aparición del virus en marzo hasta el tratamiento parlamentario de la ley de urgente consideración (LUC) presentada por el gobierno, un proyecto ómnibus con más de 500 artículos que modificaban más de 30 políticas públicas. En ese período, los partidos establecieron un sólido consenso en la arena parlamentaria en apoyo a la estrategia de confinamiento promovida por el gobierno. La segunda etapa se extiende desde ese momento hasta el ingreso a comienzos de setiembre del proyecto de Presupuesto 2020-2025. Durante ese lapso el gobierno procesó una lenta pero sostenida apertura de la economía y la sociedad, al tiempo que se incrementaron las disputas entre el gobierno y la oposición en torno a las políticas del gobierno para enfrentar las consecuencias de la pandemia.

El trabajo está ordenado en cuatro secciones. La primera describe las características institucionales del sistema político uruguayo. La segunda analiza la etapa de consenso en el 
Parlamento mostrando cómo estaba el país a la llegada del virus, las decisiones adoptadas por el gobierno y la cooperación alcanzada por los actores en un marco de incertidumbre. La tercera sección analiza la etapa de apertura y la emergencia de la confrontación gobierno-oposición a partir del ingreso a la arena parlamentaria de las principales iniciativas legislativas del poder ejecutivo. La cuarta sección presenta algunas conclusiones finales sobre el desempeño del Parlamento en el marco de la pandemia.

\section{Nuevo gobierno, nueva legislatura.}

Uruguay cuenta con un régimen de gobierno presidencial atenuado. El presidente tiene poderes legislativos moderados y sus ministros son responsables ante un poder legislativo bicameral con capacidad de interpelación y censura ministerial. Esta distribución de prerrogativas constitucionales transforma al Parlamento en una institución central del proceso de gobierno pues la aprobación de leyes es el único camino para modificar las políticas públicas. La Cámara de Senadores está integrada por 30 miembros, electos por representación proporcional en una circunscripción única nacional, más la Vicepresidenta de la República. La Cámara de Representantes cuenta con 99 diputados electos por representación proporcional en diecinueve circunscripciones plurinominales ${ }^{2}$. La alta proporcionalidad del Parlamento combinada con la doble vuelta presidencial, incentiva la emergencia de pequeños partidos que normalmente logran pequeñas representaciones en la cámara baja (BUQUET; CHASQUETTI; MORAES, 1998). El diseño institucional se complementa con institutos de democracia directa que permiten derogar leyes aprobadas por el Parlamento (referéndums) o realizar modificaciones a la Constitución (plebiscitos). Desde la restauración de la democracia en 1985, los institutos de democracia directa han sido utilizados para bloquear reformas pro-mercado o para introducir cláusulas de protección en la Constitución para ciertos grupos de presión como los jubilados y pensionistas o los defensores de los recursos hídricos (ALTMAN, 2011).

Los partidos políticos uruguayos cuentan con organizaciones extendidas en todo el país, con fracciones internas bien organizadas y liderazgos políticos de prestigio. Las reglas electorales contribuyen a que los partidos sean actores parlamentarios disciplinados y que su orientación predominante sea de tipo programático. Los lideres partidarios desarrollan su actividad en el Senado y en el poder ejecutivo - para el caso del partido de gobierno- y controlan con facilidad las carreras políticas dentro de los partidos. El sistema de partidos presenta un formato de multipartidismo moderado, con dos partidos mayores -el Frente Amplio y el Partido Nacional-, dos partidos medianos

\footnotetext{
${ }^{2}$ Sin embargo, a la hora de asignar los asientos, primero se considera la votación de los partidos y fracciones en todo el país y en base a esa distribución, se asignan las bancas en las circunscripciones (ningún partido obtiene menos bancas que la que determina su votación nacional). Al respecto, ver (BUQUET; CHASQUETTI; MORAES, 1998).
} 
y varios partidos pequeños. El número efectivo de partidos en la actual legislatura es de 3,26 en el Senado y de 3,31 en la cámara baja (CHASQUETTI; GARCÍA ORTÍZ, 2020)

Dentro del Parlamento, los partidos se organizan en bancadas con reglamentos internos que regulan el comportamiento de sus miembros en la presentación de proyectos, iniciativas de interpelación y votaciones. Los partidos negocian en cada cámara la distribución de posiciones y el tamaño de las comisiones permanentes y los líderes de las fracciones supervisan la designación de legisladores en esos organismos (CHASQUETTI, 2014). El Parlamento uruguayo funciona en base a reglas abiertas pues no existen organismos pre-floor que controlen la agenda del plenario y el proceso decisorio admite modificaciones en todas sus etapas legislativas (CALVO; CHASQUETTI, 2016).

El resultado de las elecciones de 2019 determinó el triunfo de la oposición luego de 15 años de gobierno del partido de centro-izquierda, Frente Amplio. El presidente electo, Luis Lacalle Pou del Partido Nacional, había quedado segundo en la primera ronda (a nueve puntos del candidato oficialista) pero un acuerdo con los restantes partidos de oposición le permitió alcanzar una ajustada victoria en el balotaje. La alianza ganadora se construyó a partir de un acuerdo programático denominado "Compromiso por el País" que establecía trece líneas de acción gubernativa. La “coalición multicolor”, como se autodenominó, controla la mayoría absoluta en ambas cámaras lo cual garantiza un escenario favorable pare el gobierno ya sea para impulsar legislación como para proteger a los ministros de posibles mociones de censura.

Cuadro 1 - Distribución de bancas en el Parlamento ( $48^{\circ}$ y $49^{\circ}$ Legislatura)

\begin{tabular}{llcccc}
\hline & Partidos & \multicolumn{2}{c}{ Cámara de Senadores } & \multicolumn{2}{c}{$\begin{array}{c}\text { Cámara de } \\
\text { Representantes }\end{array}$} \\
\hline \multirow{3}{*}{ Coalición } & Partido Nacional & 11 & $35 \%$ & 30 & $30 \%$ \\
Multicolor & Partido Colorado & 4 & $13 \%$ & 13 & $13 \%$ \\
& Cabildo Abierto & 3 & $10 \%$ & 11 & $11 \%$ \\
& Partido Independiente & - & - & 1 & $1 \%$ \\
& Partido de la Gente & - & - & 1 & $1 \%$ \\
\hline \multirow{2}{*}{ Oposición } & Frente Amplio & 13 & $42 \%$ & 42 & $42 \%$ \\
& P.E.R.I. & - & - & 1 & $1 \%$ \\
\hline
\end{tabular}

Fuente: Elaboración propia en base al Banco de Datos de FCS-UdelaR

Lacalle Pou asumió su cargo el $1^{\circ}$ de marzo de 2020, trece días antes de la aparición de la pandemia. Su gabinete estaba integrado por 7 ministros del Partido Nacional (entre ellos Economía, Interior, Relaciones Exteriores y Defensa), 3 del Partido Colorado, 2 de Cabildo Abierto, y 1 del Partido Independiente. La distribución de carteras respetó el peso parlamentario de cada partido de la 
coalición. El índice de congruencia del gabinete presentó un valor de 0,807 , lo cual indica que el diseño de gobierno era consistente con el formato de coalición3.

El programa de la coalición multicolor estaba orientado a reactivar la economía, corregir algunos indicadores macroeconómicos -como el déficit fiscal, la inflación y el desempleo- y enfrentar decididamente los problemas de inseguridad que sufría el país. Para impulsar sus principales medidas, el poder ejecutivo anunció que enviaría al Parlamento un proyecto de ley, tipo ómnibus con más de 500 artículos, con el rótulo de urgente consideración, que modificaba más de 30 políticas públicas en un plazo no mayor a los noventa días ${ }^{4}$. Esa decisión del gobierno prometía desatar una intensa batalla entre gobierno y oposición en la arena parlamentaria, pero la aparición del coronavirus modificó completamente el escenario político. El conflicto distributivo que las políticas del nuevo gobierno podría generar, debería esperar por un momento más propicio. La percepción del riesgo de los principales actores fue más fuerte por lo que el sistema político cerró filas en torno a la estrategia sanitaria del gobierno y que a la postre, resultaría exitosa.

\section{El Parlamento en la etapa de confinamiento: un tiempo de consenso}

En comparación con otros países de la región, Uruguay estaba bien preparado para absorber el impacto de la pandemia. El Estado cuenta con importantes capacidades empresariales (teléfonos, energía, aguas, servicios bancarios, seguros, etc.) y desarrolla políticas sociales en múltiples áreas como la salud, la educación o las pensiones. El Sistema Nacional Integrado de Salud (SNIS), en particular, es un estructura poderosa que reúne a los hospitales públicos y a las instituciones privadas de asistencia médica. El SNIS atiende al 90\% de la población con una inversión de casi 6 puntos porcentuales del PBI (22\% del presupuesto nacional). El resto de los ciudadanos cuentan con atención médica específica (militares y policía) o con seguros privados integrales diseñados para sectores de altos ingresos. Otra institución importante es el Banco de Previsión Social (BPS), encargado del pago de las jubilaciones y pensiones y de otras prestaciones relevantes como el seguro de desempleo o las asignaciones familiares a los hogares de bajos ingresos. Finalmente, debe mencionarse al Ministerio de Desarrollo Social, encargado de un conjunto de programas focalizados en la población más

\footnotetext{
${ }^{3}$ El Índice de Congruencia del Gabinete de (AMORIN NETO, 1998) permite evaluar el grado de justicia distributiva con que se designan los ministerios. El cálculo compara la proporción de carteras recibidas por cada partido con la proporción de bancas que aporta en la coalición legislativa. El valor 1 representa la máxima congruencia.

${ }^{4}$ El Poder Ejecutivo cuenta con la prerrogativa de enviar al Legislativo proyectos de urgente consideración con un plazo para su tratamiento. Cada cámara cuenta con 30 días y en caso de existir desacuerdos entre ambas cámaras, se establece un plazo adicional de 15 días para la primera; en caso de persistir las diferencias habrá un plazo adicional de 10 días para que la Asamblea General (reunión de ambas cámaras) decida. Si alguno de esos plazos no se cumple, el proyecto se transforma automáticamente en ley. Los presidentes uruguayos han utilizado estos procedimientos en raras ocasiones (menos de quince proyectos durante el período de vigencia de la Constitución de 1967).
} 
vulnerable. El Estado uruguayo también cuenta con capacidades tecnológicas. La empresa estatal ANTEL conecta a internet al $85 \%$ de las familias, de los cuales tres cuartas partes cuenta con fibra óptica en sus hogares. El Plan Ceibal, desarrollado desde 2005 a partir de la iniciativa One Laptop per Child, funciona como una plataforma educativa pública que provee un conjunto de programa y recursos educativos para la enseñanza y el aprendizaje. Los avances en conectividad también permitieron un fuerte desarrollo de medios de pago electrónicos a partir de la inclusión financiera de la población formal, estimada en un 77\% de la población económicamente activa (CHASQUETTI, 2020).

Por otra parte, a comienzos de 2020, la economía uruguaya no había entrado en recesión. Los organismos multilaterales y el gobierno saliente, habían pronosticado un crecimiento anual de 2,5\% del PBI. Si bien el déficit fiscal se encontraba en 4,5\% y la desocupación había alcanzado un $10 \%$, las expectativas generales eran de optimismo sobre todo por la asunción de un nuevo gobierno. A eso se sumaba una situación social muy estable con bajos niveles de pobreza (9\% de los hogares) e importantes niveles de igualdad según consignan la mayoría de las mediciones internacioanles (los más altos en América Latina según CEPAL).

Con esa situación como telón de fondo, el viernes 13 de marzo se conocieron los primeros cuatro casos de coronavirus en el país. Esa misma noche, el presidente Lacalle Pou realizó una conferencia de prensa para declarar el estado de emergencia sanitaria. Las medidas implementadas suspendieron los espectáculos públicos, cerraron los centros turísticos, cancelaron las actividades culturales, cerraron las fronteras y prohibieron el desembarco de cruceros y buques comerciales provenientes de zonas de alto riesgo (Decretos 93/2020, 94/2020 y 100/2020) ${ }^{5}$. Un decreto del lunes 16 de marzo (101/2020) suspendió por quince días los cursos regulares en todos los niveles de la enseñanza y vencido ese plazo, se suspendieron las clases presenciales por tiempo indeterminado. Otro decreto del 23 de marzo (103/2020) cerró los aeropuertos, prohibió el ingreso de personas provenientes de Argentina y Brasil, estableciendo procedimientos para el manejo de la pandemia en las ciudades binacionales de frontera. Finalmente, un decreto del 25 de marzo (109/2020) permitió a los trabajadores mayores de 65 años permanecer en sus hogares hasta el 31 de julio, percibiendo el salario si realizaban teletrabajo o cobrando un seguro de desempleo si esa modalidad no pudiese ser implementada (CHASQUETTI, 2020).

Durante los primeros quince días de la pandemia, el gobierno realizó diez conferencias de prensa en el horario central de televisión con el fin de informar sobre la situación sanitaria y explicar las medidas que se iban adoptando. La comunicación fue liderada por el presidente Lacalle Pou y el

\footnotetext{
${ }^{5}$ Para consultar los decretos presidenciales, ver https://www.presidencia.gub.uy/normativa/2020-2025/decretos (consultado el 14 de julio).
} 
secretario de presidencia, Álvaro Delgado, quienes exhortaron a la población a "quedarse en casa". Esta política supuso en los hechos una brusca clausura de la vida social. Pese a ello, algunos actores relevantes criticaron las medidas por considerarlas insuficientes. El Sindicato Médico del Uruguay, el ex presidente Tabaré Vázquez (reconocido oncólogo), la central sindical e incluso el propio ministro de Salud Pública, se inclinaban por el establecimiento de una cuarentena total, pero el presidente Lacalle Pou prefirió apostar a la "libertad responsable" de los ciudadanos. Apoyado en su visión liberal, el presidente creía que cuánto más intenso fuera el cierre, más difícil sería la recuperación económica del país una vez superada la crisis. Según Google Uruguay, la asistencia a actividades recreativas se redujo en un $75 \%$ en la segunda quincena de marzo; las visitas a lugares públicos, un 79\%; el uso del transporte público, un 71\%; y la circulación en supermercados y tiendas de alimentos, un $45 \%{ }^{6}$.

Mientras el Poder Ejecutivo adoptaba esas restricciones, el Parlamento continuó sesionando con reuniones breves que no excedían las dos horas de duración. Su principal objetivo era tratar los proyectos de ley relativos a la crisis sanitaria enviados por el gobierno. En las semanas previas, ambas cámaras habían elegido a sus autoridades y habían completado el proceso de distribución de posiciones entre los partidos en las comisiones permanentes. La organización y funcionamiento de las bancadas permitía imaginar que esta sería una legislatura marcada por la típica confrontación entre legisladores oficialistas y legisladores opositores. Sin embargo, en las semanas posteriores a la aparición del virus, la lógica de funcionamiento cambiaría tanto en términos organizacionales como políticos.

La información disponible muestra que en los primeros 45 días de pandemia, la frecuencia de reuniones de los plenarios de ambas cámaras se mantuvo en niveles similares o incluso superiores a los de la legislatura previa (ver gráficos 1 y 2). Sin embargo, el ritmo de reuniones de las comisiones permanentes se retrasó abruptamente debido a las precauciones sanitarias adoptadas por la institución. Muchas sesiones fueron canceladas y varios proyectos fueron tratados por el plenario sin un dictamen específico de una comisión. En el primer mes y medio de pandemia se realizaron sólo 13 reuniones de comisiones permanentes cuando en la legislatura pasada, en igual período, se habían realizado 76 (ver cuadro 3 ).

\footnotetext{
6 https://ladiaria.com.uy/coronavirus/articulo/2020/4/como-cambio-la-movilidad-en-uruguay-tras-los-primeros-casos-decoronavirus-segun-los-datos-de-google/ (consultado el 30 de julio de 2020).
} 
Gráfico 1 - Sesiones de la Cámara de Representantes. $48^{\circ}$ Legislatura (2015) vs. $49^{\circ}$ Legislatura (2020)

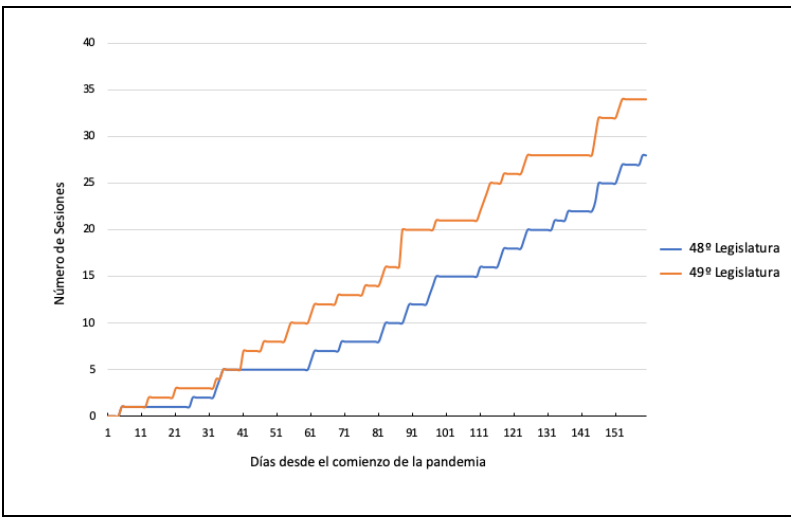

Fuente: Elaboración propia en base a datos del Sistema de Información Parlamentaria.
Gráfico 2 - Sesiones de la Cámara de Senadores. $48^{\circ}$ Legislatura (2015) vs. $49^{\circ}$ Legislatura (2020)

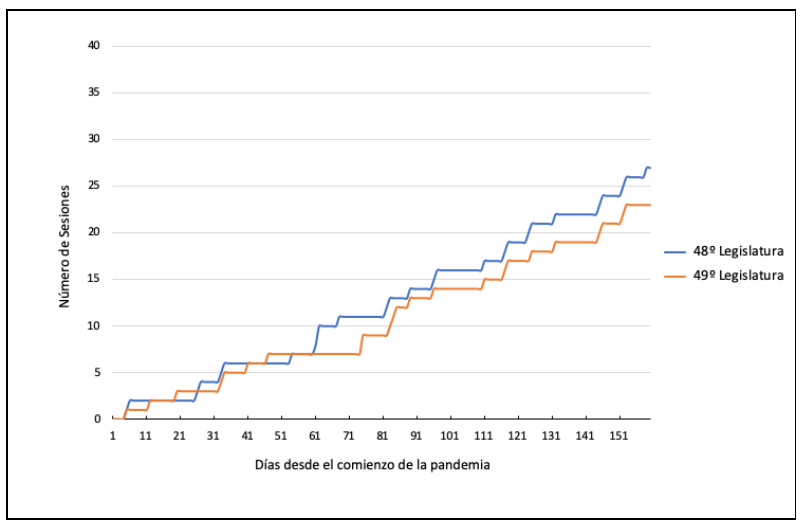

Fuente: Elaboración propia en base a datos del Sistema de Información Parlamentaria.

Gráfico 3 - Sesiones de las comisiones de ambas cámaras. $48^{\circ}$ Legislatura (2015) vs. $49^{\circ}$ Legislatura (2020)

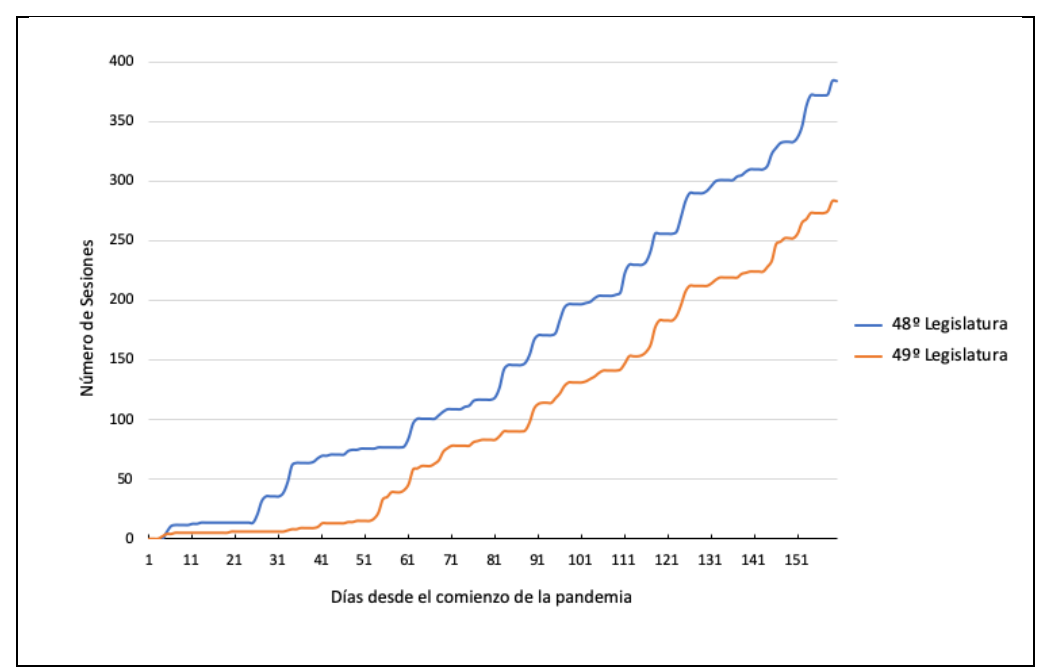

Fuente: Elaboración propia en base a datos del Sistema de Información Parlamentaria.

La aparición de la pandemia también afectó la composición de las cámaras. En la segunda quincena de marzo, los legisladores de edad más avanzada y que por esa condición pertenecían al grupo de riesgo de contagio, optaron por recluirse en sus domicilios y dar paso a sus suplentes mas jóvenes. De esta manera, senadores experimentados como José Mujica, Lucía Topolansky, Eduardo Bonomi y Danilo Astori del Frente Amplio, Julio Sanguinetti del Partido Colorado y Sergio Abreu del Partido Nacional, fueron reemplazados por figuras de menor renombre. 
Durante el primer mes y medio de pandemia, el poder ejecutivo presentó 13 proyectos de ley - 7 referidos a la crisis sanitaria- que el Parlamento analizó y aprobó en un tiempo record (14 días promedio desde su presentación hasta su promulgación) y con el voto favorable de todos los componentes de ambas cámaras. En el mismo lapso, los parlamentarios introdujeron 3 proyectos de ley vinculados a la situación de pandemia que fueron aprobados en condiciones similares (6 días en promedio y sin votos contarios). Las tasas de efectividad legislativa, calculada como la proporción de proyectos sancionados sobre el total de proyectos enviados, adquirieron valores inusitados para ese período, alcanzando en el caso del Poder Ejecutivo un $83 \%$ en el día 70 de la pandemia, y $17 \%$ en el caso del Poder Legislativo en el día 34 (ver gráfico 4$)^{7}$.

Gráfico 4 - Tasa de Efectividad de los Poderes

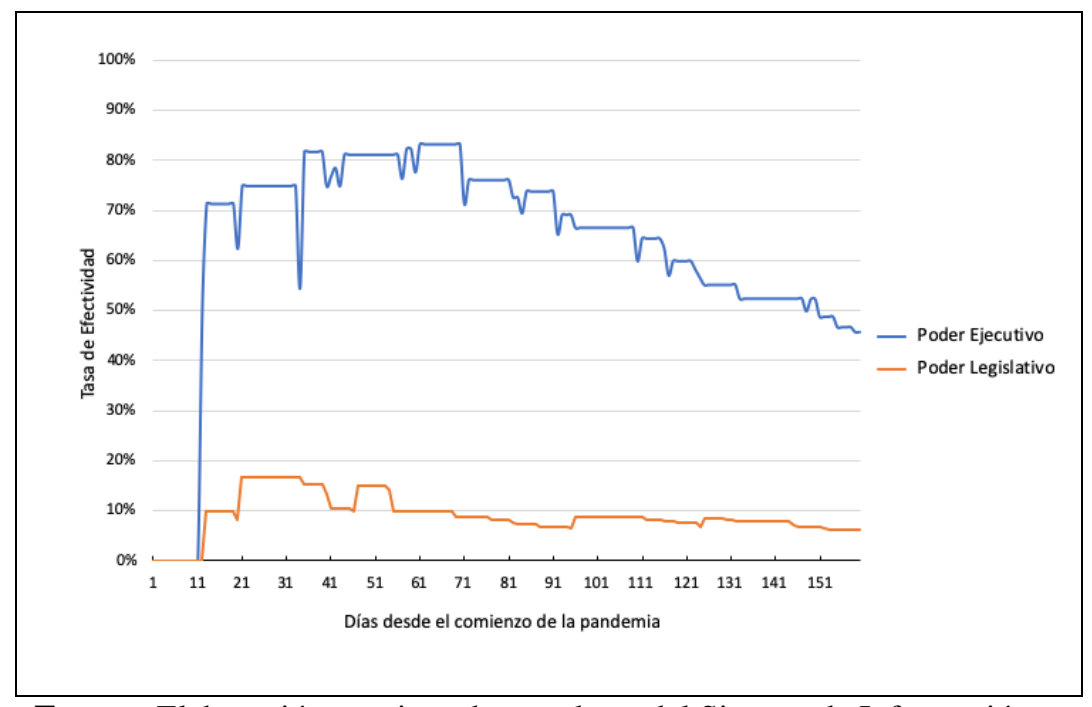

Fuente: Elaboración propia en base a datos del Sistema de Información Parlamentaria.

La normativa aprobada en los primeros 45 días de pandemia es diversa pero tiene una pieza legislativa principal: la creación del Fondo Solidario Covid-19 ( N $\left.^{\circ} 19.874\right)$. Esta iniciativa tuvo por objetivo solventar las políticas de protección social, las crecientes erogaciones del sistema de salud, las actividades del Sistema Nacional de Emergencias y las prestaciones extras del seguro de desempleo. El Fondo se formó con las utilidades del Banco República y de la Corporación Nacional

\footnotetext{
${ }^{7}$ Los estudios sobre el desempeño legislativo de los poderes en Uruguay muestran que las tasas de eficacia aumentan con el transcurso del mandato legislativo. Durante el período del presidente Mujica (2010-2015) la tasa de eficacia del Poder Ejecutivo alcanzó el 78\% en el último año. En el primer año, ningún presidente alcanzó a tener tasas de eficacia superiores al 30\%. El Poder Legislativo lógicamente presenta tasas de eficacia muy inferiores porque los legisladores están divididos en partidos y presentan proyectos sin coordinar. Al respecto ver LANZARO ET.AL. (1999) y CHASQUETTI, BUQUET Y MORAES (2014).
} 
para el Desarrollo correspondientes al 2019; las donaciones de dinero que pudieran realizar personas o empresas, y los préstamos internacionales que el país tomaría. El proyecto también creó el "Impuesto Emergencia Sanitaria COVID-19", que gravaba con tasas de entre un 5\% y un 20\% a los salarios del nivel superior de servidores del Estado, gobiernos departamentales, entes autónomos, servicios descentralizados y poder judicial. El impuesto fue aplicado durante dos meses y alcanzó a toda la élite política (presidente, ministros, parlamentarios, autoridades departamentales, ministros de la Suprema Corte) y a las máximas autoridades de la burocracia pública (directores de empresas públicas y gerentes de la administración pública).

El Parlamento también aprobó una norma que regulaba la contribución de las empresas del sector agropecuario al Fondo COVID-19 ( ${ }^{\circ}$ 19.884) y otra que creaba un subsidio mensual para los comerciantes monotributistas ( $\mathrm{N}^{\mathrm{o}}$ 19.877). Otras normas sancionadas determinaban exoneraciones tributarias a las empresas industriales y del comercio $\left(\mathrm{N}^{\mathrm{o}} 19.872\right)$ y a las empresas unipersonales y cooperativas de menor porte $\left(\mathrm{N}^{\mathrm{o}}\right.$ 19.886). También se dispuso una reducción transitoria a la contribución inmobiliaria para las predios rurales $\left(\mathrm{N}^{\mathrm{o}}\right.$ 19.884) y se votaron dos leyes que afectaban al sector de la salud: regulación de la telemedicina ( $\mathrm{N}^{\mathrm{o}}$ 19.869) y definición del COVID-19 como enfermedad profesional del personal sanitario ( $\left.\mathrm{N}^{\circ} 19.873\right)$.

Finalmente, una norma extendió en forma extraordinaria los plazos procesales de la justicia ( $\mathrm{N}^{\mathrm{o}}$ 19.879) y otra, prorrogó la fecha de realización de las elecciones departamentales y municipales previstas para el 10 de mayo de 2020 ( $\mathrm{N}^{\circ}$ 19.875). Esta última ley ilustra con claridad la lógica de funcionamiento consensual que adquirió el Parlamento durante las primeras semanas de pandemia. Como la Constitución establece en el inciso $9^{\circ}$ del artículo 77 que los comicios departamentales se deben realizar "el segundo domingo del mes de mayo del año siguiente a las elecciones nacionales", los partidos pactaron una solución que facultaba a la Corte Electoral a prorrogar, por única vez, la fecha de los comicios. La Corte finalmente determinaría que las elecciones subnacionales se realizarían el domingo 27 de setiembre.

En materia de supervisión del gobierno, el Parlamento no desarrolló un gran despliegue de sus facultades durante esta primera etapa. La escasa actividad de las comisiones impidió las convocatorias de ministros a esos organismos. Tampoco se registraron llamados a sala de ministros con el objetivo de interpelarlos ${ }^{8}$. La principal actividad de control consistió en el envío de pedidos de informes (preguntas escritas) a los ministerios y agencias del gobierno ${ }^{9}$. Sin embargo, el número de solicitudes presentadas por los legisladores en ese lapso no fue alto, sobre todo si se le compara

\footnotetext{
${ }^{8}$ Para convocar al plenario a los ministros, se requiere de la firma de un tercio de los miembros de alguna de las cámaras (artículo 119 de la Constitución).

${ }^{9}$ Los pedidos de informes son presentados por los legisladores en forma individual y no requieren de una aprobación de la cámara (artículo 118 de la Constitución).
} 
con otros países de la región ${ }^{10}$. Aún así, la preocupación de los legisladores por la crisis sanitaria fue mayor en las primeras semanas: en el día 20 de la pandemia, 7 de cada 10 pedidos de informes estaban referidos a ese tema. Esa proporción se mantuvo constante durante los primeros dos meses, pero para el día 55 la proporción había caído a la mitad.

Gráfico 5 - Pedidos de Informes.

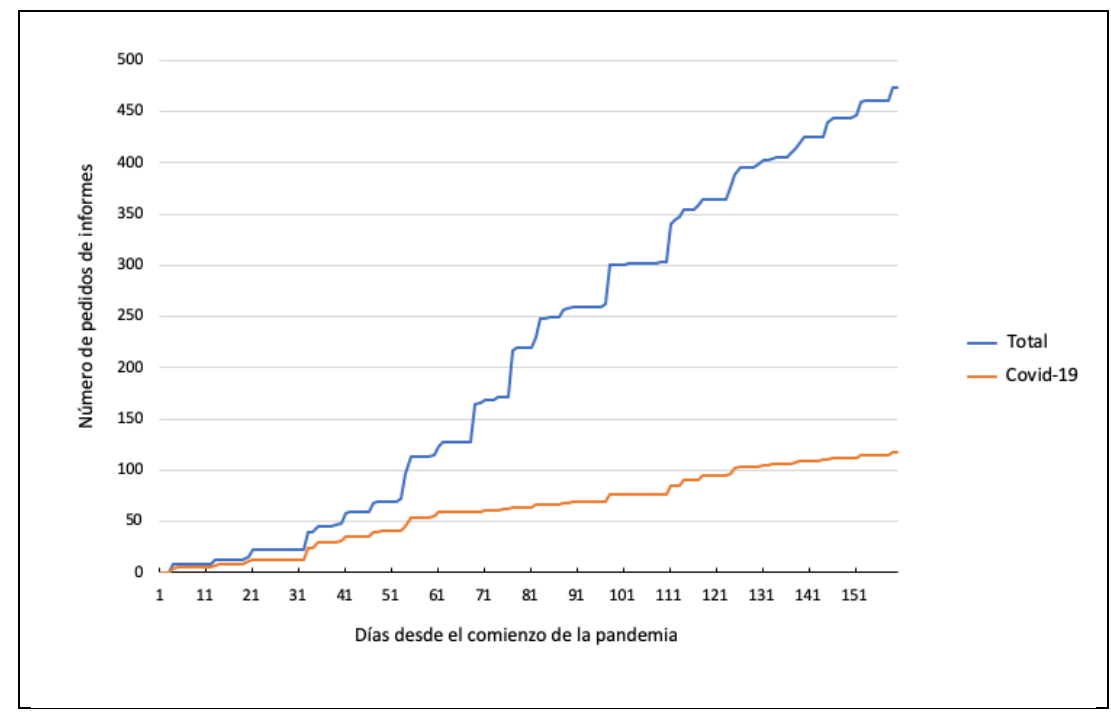

Fuente: Elaboración propia en base a datos del Sistema de Información Parlamentaria.

Los datos presentados ilustran un funcionamiento parlamentario de tipo consensual. Los legisladores de la coalición de gobierno apoyaron la estrategia diseñada por el poder ejecutivo, en tanto los del Frente Amplio asumieron una actitud cooperativa. Incluso, seis días después de haber sido declarada la emergencia sanitaria, la bancada de legisladores del Frente Amplio ofreció al gobierno "un acuerdo nacional" para "combatir la pandemia y sus consecuencias económicas y sociales" ${ }^{11}$. Si bien el gobierno nunca respondió a la propuesta, el presidente y sus ministros mantuvieron contactos permanentes con las autoridades de este partido. En el Parlamento, los coordinadores de bancada de los diferentes partidos trabajaron para establecer una agenda legislativa centrada en la crisis sanitaria. En la medida que los indicadores del COVID-19 fueron mejorando, el escenario de cooperación daría paso a un escenario de mayor conflicto, muy parecido al esperado en los días previos a la aparición del virus.

\footnotetext{
${ }^{10}$ Por ejemplo, en los primeros 30 días de pandemia el Parlamento uruguayo presentó 23 pedidos de informes de los cuales 13 estaban vinculados al tema Covid-19. En Chile, por ejemplo, en el mismo lapso, se cursaron 423 solicitudes similares (preguntas escritas).

${ }^{11}$ Ver https://www.montevideo.com.uy/Noticias/Bancada-del-FA-reclama-al-gobierno-medidas-para-disminuir-efectosnegativos-del-Covid-19-uc747534 (Consultado el 28/08/202).
} 


\section{EI Parlamento ingresando a la nueva normalidad.}

Durante el primer mes de la pandemia el aumento de contagios en Uruguay tuvo un comportamiento lineal. El brote inicial fue controlado mediante un rastreo exhaustivo de los contactos de las personas contagiadas y para el mes de abril ya comenzaban a percibirse los primeros resultados del confinamiento voluntario. El indicador más relevante para apreciar este fenómeno es la evolución del número de personas que cursaban la enfermedad. Entre el día 20 de la pandemia y el día 98, la cifra de contagiados activos cayó de 302 a sólo 12. A fines de mayo (día 80 de la pandemia), el número de personas fallecidas apenas superaba las dos decenas y el número de test diarios superó el millar. Para fines de julio (día 140 de la pandemia), las muertes por Covid-19 eran 35 y el número de test diarios superaba los dos mil.

Gráfico 6 - Casos acumulados y casos activos en Uruguay.

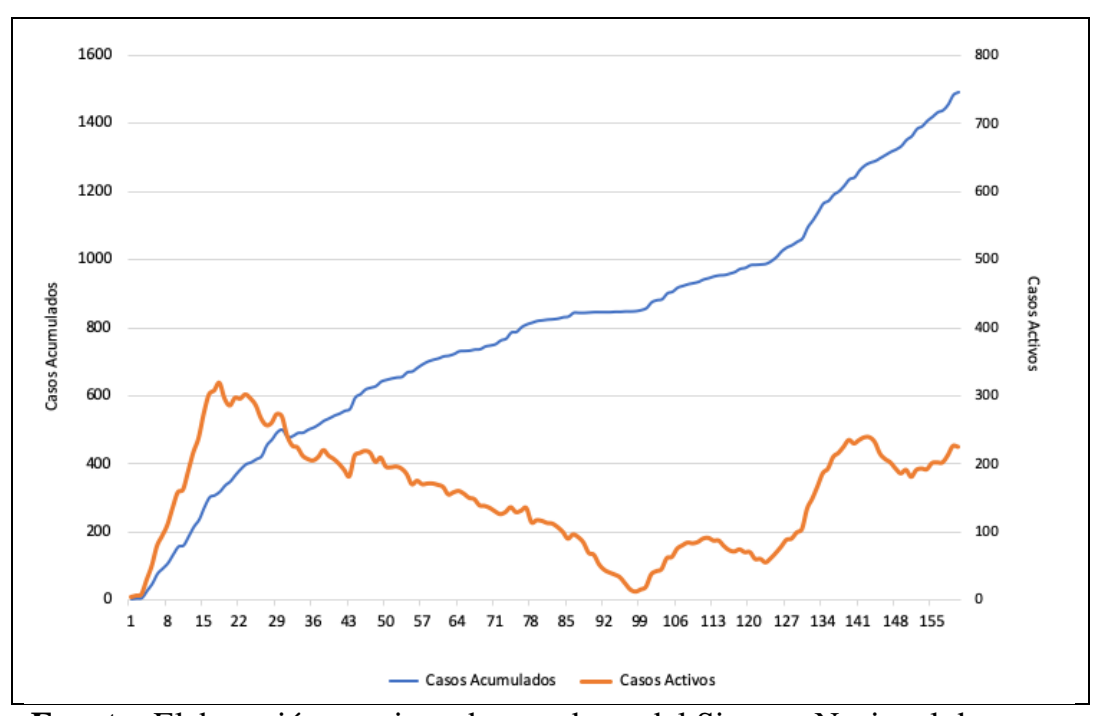

Fuente: Elaboración propia en base a datos del Sistema Nacional de Emergencia.

Los resultados auspiciosos impulsaron al gobierno a iniciar el proceso de reapertura económica y social bajo estrictos protocolos de seguridad. El primer paso se dio el 22 de abril con el retorno de las clases presenciales en las escuelas rurales. En las ciudades, el retorno de las escuelas y centros de educación secundaria se produjo en el mes de junio. En la primera quincena de ese mes también reabrieron los grandes centros comerciales, bares, restaurantes e iglesias. Durante el mes de julio, el gobierno continuó aprobando protocolos de reapertura en diferentes áreas de la actividad económica y social. A comienzos de agosto, regresaron los teatros, los museos y los espectáculos deportivos. 
El Parlamento mientras tanto fue intensificando su actividad. A fines de mayo, el funcionamiento de los plenarios de las cámaras y comisiones ya era normal. El 23 de abril, el Poder Ejecutivo envió al Parlamento su prometida ley de urgente consideración, conocida popularmente como LUC. El Frente Amplio criticó la decisión por entender que todavía no estaban dadas las condiciones sanitarias para tratar un proyecto tan relevante, pero la coalición mayoritaria impuso su mayoría. Durante el trámite legislativo, la LUC fue analizada por comisiones especiales integradas por 15 miembros en el Senado y 21 en la Cámara de Representantes que realizaron más de cuarenta sesiones (32 en el Senado y 12 en Representantes) y contó con la presencia de más de cien organizaciones sociales. El proyecto que originalmente contaba con 507 artículos relativos a temas como la seguridad pública, la educación, el agro, la gestión pública, la creación de un ministerio y nuevas agencias del gobierno, quedó reducido a 476 en su versión final, lo cual indica que existieron costos de transacción altos. La votación del proyecto en ambas cámaras fue dividida, pero el Frente Amplio apoyó el 43\% de los artículos en las votaciones particulares. El 9 de julio de 2020, el Poder Ejecutivo promulgó la ley y con ella, se dio inicio a lo que podría considerarse la nueva normalidad en política.

Figura 1 - Cronología de los principales eventos parlamentarios en 2020.

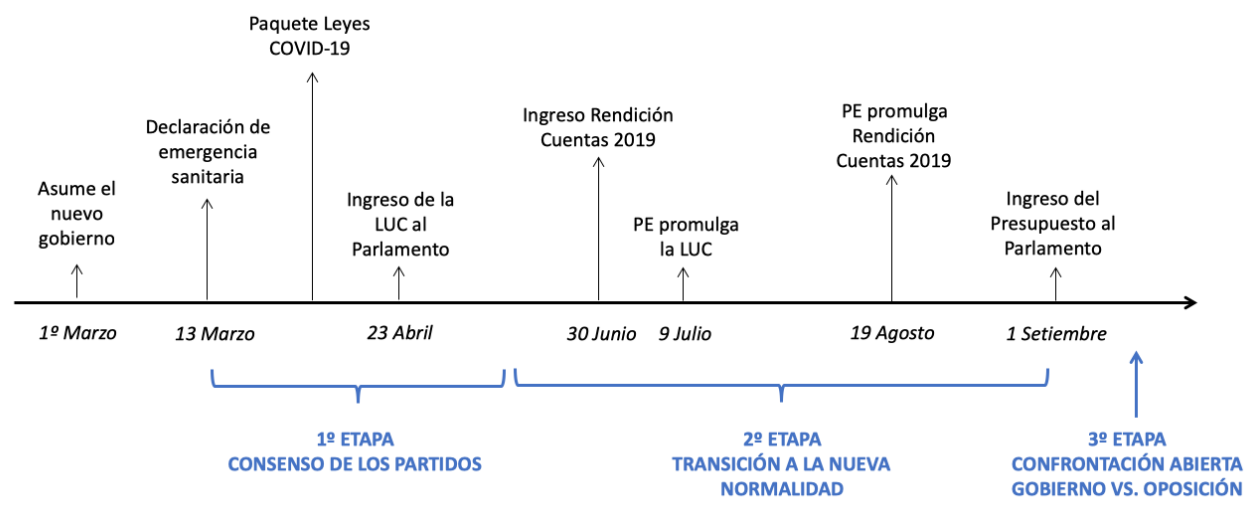

Fuente: Elaboración propia en base al Sistema de Información Parlamentaria y reportes de prensa.

La siguiente batalla entre el gobierno y la oposición en la arena parlamentaria fue la ley de Rendición de Cuentas de 2019. Por tratarse de una norma presupuestal relativa al ejercicio del último año del gobierno saliente, su discusión adquirió características diferentes a la observada durante la LUC. Los parlamentarios del Frente Amplio defendieron los resultados de su gobierno en materia económica, en tanto los oficialistas desarrollaron su crítica a los resultados fiscales y la desacelaración 
de la economía en ese año. La ley fue votada por todos los partidos por una simple lógica procedimental: mientras los legisladores de la coalición de gobierno entendían que la rendición debía ser aprobada por una simple cuestión contable, los del Frente Amplio la apoyaron por entender que los resultados eran buenos. La discusión desarrollada dejó un escenario político más polarizado que anticipaba la siguiente batalla: la ley de Presupuesto 2020-2025 que debería ser presentada por el gobierno el $1^{\circ}$ de setiembre, tal cual lo establece la Constitución.

Entre el $1^{\circ}$ de marzo y el 30 de agosto, el Parlamento aprobó 32 leyes de las cuales 22 consiguieron el voto por unánime de todos los miembros de ambas cámaras. Las restantes leyes se dividen en dos grupos: las que contaron con el apoyo de más del 90\% de los legisladores (6 leyes) y las que expresan una clara división de preferencias (4 leyes). Estas últimas fueron sancionadas luego del $1^{\circ}$ de julio lo cual evidencia que el consenso político motivado por la pandemia había dejó paso al conflicto entre el gobierno y la oposición, señal inequívoca de estar ingresando en la nueva normalidad política.

En materia de supervisión del gobierno, el Parlamento continuó utilizando a los pedidos de informes como su principal herramienta. Si bien el 4 de junio, un diputado de Cabildo Abierto -partido miembro de la coalición de gobierno- convocó al plenario a cuatro ministros del gobierno para ser interpelados, ese acto no puede ser considerado un episodio típico de control legislativo pues su motivación era indagar sobre decisiones adoptadas por la anterior administración (el acuerdo de con la empresa finlandesa UPM para la construcción de una planta de celulosa en el interior del país). El evento culminó con una declaración crítica al gobierno anterior y un respaldo explícito a los nuevos gobernantes.

Tal cual se observara en el gráfico 5, los pedidos de informe continuaron creciendo sostenidamente. Para el día 160 de la pandemia (19 de agosto), ya se habían cursado 473 pedidos de informes de los cuales 216 habían sido respondidos por los organismos de gobierno. El Frente Amplio había cursado 287 (61\%), en tanto los legisladores de la oposición, 186 (39\%). Paradojalmente, las preferencias en los destinos de los pedidos de informes de uno y otro bloque tienden a coincidir, aunque no las razones de su presentación. Mientras los legisladores del Frente Amplio manifestaban interrogantes sobre las políticas públicas que comenzaba a desarrollar el nuevo gobierno, los oficialistas centraron sus preguntas en los resultados alcanzados por la anterior administración. 
Gráfico 7. Pedidos de Informes según destino.

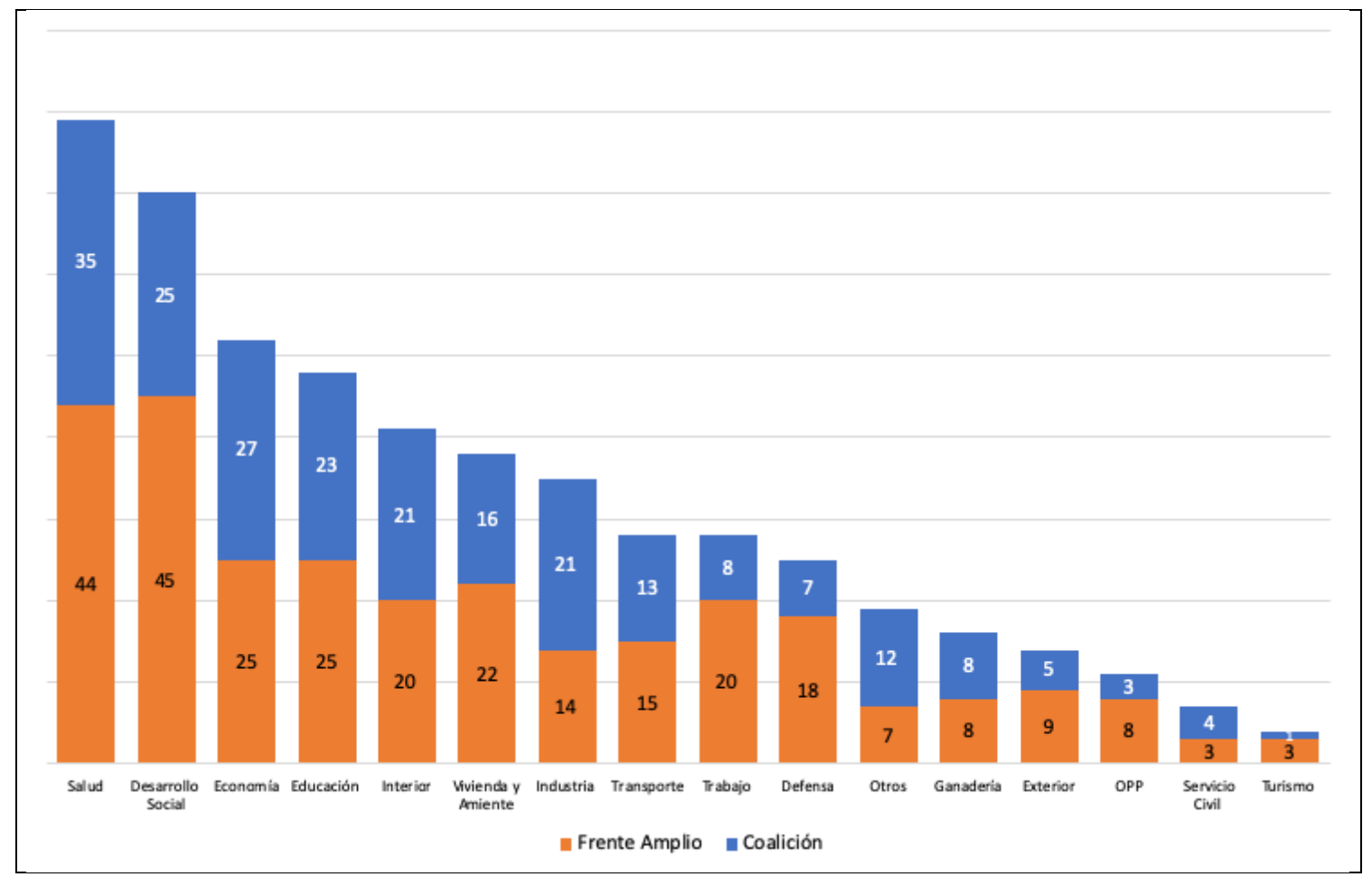

Fuente: Elaboración propia en base a datos del Sistema de Información Parlamentaria.

\section{Conclusiones}

La pandemia del COVID-19 en Uruguay muestra el caso de un Parlamento que consiguió eludir los principales problemas que aquejaron a la mayoría de las legislaturas democráticas del mundo. El Parlamento como institución cumplió un papel relevante, aprobando leyes, manteniendo importantes niveles de deliberación pública sin abdicar de su capacidad de control del gobierno. Su capacidad de adaptación organizacional y política a la nueva situación de crisis responde a la capacidad de los actores partidarios para comprender la situación política.

Al comienzo de la pandemia, los partidos percibieron la situación de riesgo, particularmente porque países como España, Francia o Italia se encontraban al borde del colapso de los sistemas sanitarios. Esa percepción de riesgo orientó a los actores a la cooperación y el entendimiento. Las cuestiones en disputa fueron diferidas en el tiempo y la agenda parlamentaria se concentró casi exclusivamente en las medidas para enfrentar la crisis sanitaria. La mayoría de las leyes sancionadas en los primeros dos meses contaron con el apoyo de todos los partidos y un delay legislativo de tan 
sólo 12 días promedio. El Parlamento mantuvo un funcionamiento básico con plenarios de las cámaras de corta duración, comisiones permanentes en receso y legisladores seniors de licencia.

Los resultados de la buena performance del país se transformaron rápidamente en un botín de disputa. Mientras el gobierno desarrolló un sostenido credit claming argumentando que los éxitos sanitarios eran producto de su estrategia, el Frente Amplio hizo hincapié en las fortalezas institucionales que el país desarrolló durante los quince años de gobierno de izquierda (sistema integrado de salud, organismos de protección social, desarrollo tecnológico, etc.). En perspectiva, puede afirmarse que ambos actores tienen un poco de razón.

La apertura de las actividades coincidió con la introducción de la principal pieza legislativa del gobierno, la LUC. Su discusión es un buen ejemplo del esfuerzo que los partidos hicieron para normalizar la política sin asumir riesgos excesivos. Se formaron comisiones especiales en ambas cámaras para recibir a más de un centenar de organizaciones sociales afectadas por los cambios en la legislación. Esos encuentros estuvieron regulados por estrictos protocolos sanitarios que garantizaron el cumplimiento básico de los objetivos. Al final del camino legislativo, el proyecto fue profusamente modificado y la votación dividida en ambas cámaras marcó el inicio de una nueva etapa.

Desde entonces, el sistema político desarrolló una creciente confrontación entre el gobierno y la oposición teniendo al Parlamento como arena política privilegiada. Las leyes comenzaron a aprobarse con votaciones divididas y los debates fueron más parecidos a los esperados en marzo, si la pandemia no hubiese llegado. El ingreso de la ley de presupuesto el $1^{\circ}$ de setiembre y las reacciones que esta iniciativa desató, marcó la absoluta normalización de la política uruguaya.

\section{Referencias}

ALTMAN, D. Direct Democracy Worldwide. Cambridge University Press, 2010.

AMORIN NETO, O. Cabinet Formation in Presidential Regimes: An Análisis of 10 Latin American Countries. Meeting de la Latin American Studies Association, Illinois, September 24-26, 1998.

BAR-SIMAN-TOV, I. Covid-19 meets politics: the novel coronavirus as a novel challenge for legislatures. The Theory and Practice of Legislation, v. 8, n. 1-2, p. 11-48, maio 2020.

BUQUET, D.; CHASQUETTI, D.; MORAES, J. A. Fragmentación política y Gobierno: ¿Un enfermo imaginario?. Montevideo: CSIC-FCS, 1998. 
CALVO, E.; CHASQUETTI, D. Legislative success in open sky congresses: weak gatekeeping prerogatives and the loss of majority support. The Journal of Legislative Studies, v. 22, n. 1, p. 83-107, jan. 2016.

CHASQUETTI, D. Parlamento y carreras legislativas en Uruguay: Un estudio sobre reglas, partidos y legisladores en las Cámaras. Montevideo: Universidad de la República, 2014.

CHASQUETTI, D. ¿Cómo Uruguay enfrentó la pandemia del coronavirus? PEX. Executives, Presidents and Cabinets Politics, 2020. Disponível em: https://pexnetwork.com/2020/08/06/como-uruguay-enfrento-la-pandemia-del-coronavirus/. Acesso em: 1 jul. 2020.

CHASQUETTI, D.; GARCÍA ORTÍZ, E. El Parlamento de la alternancia. In: Elecciones Uruguay 2020. Montevideo: Forthcoming, 2020.

DRINÓCZI, T.; BIEŃ-KACAŁA, A. COVID-19 in Hungary and Poland: extraordinary situation and illiberal constitutionalism. The Theory and Practice of Legislation, v. 8, n. 12, p. 171-192, 3 maio 2020.

PINHEIRO, V. M.; ILARRAZ, M.; MESTRINER, M. T. The impacts of the COVID-19 crisis on the Brazilian legal system - a report on the functioning of the branches of the government and on the legal scrutiny of their activities. The Theory and Practice of Legislation, v. 8, n. 1-2, p. 193-212, 3 maio 2020.

POPELIER, P. COVID-19 legislation in Belgium at the crossroads of a political and a health crisis. The Theory and Practice of Legislation, v. 8, n. 1-2, p. 131-153, 3 maio 2020.

SEROWANIEC, M.; WITKOWSKI, Z. Can legislative standards be subject to 'quarantine'? The functioning of the Tablet Sejm in Poland in the COVID-19 era. The Theory and Practice of Legislation, v. 8, n. 1-2, p. 155-170, 3 maio 2020.

UHLMANN, F.; SCHEIFELE, E. Legislative response to Coronavirus (Switzerland). The Theory and Practice of Legislation, v. 8, n. 1-2, p. 115-130, 3 maio 2020. 